\title{
Effect of an Optical Whitening Toothpaste on Color Stability of Tooth-Colored Restorative Materials
}

\author{
Sedighe Sadat Hashemikamangar ${ }^{1}$ Farnoosh Hoseinpour ${ }^{2}$ Nazanin Kiomarsi ${ }^{3}$ \\ Mehrzad Gholampour Dehaki ${ }^{4}$ Mohammad Javad Kharazifard ${ }^{5}$
}

${ }^{1}$ Department of Operative Dentistry, Dental School, Tehran University of Medical Sciences, Tehran, Iran

${ }^{2}$ Operative Department, Tehran University of Medical Science, Tehran, Iran

${ }^{3}$ Department of Operative Dentistry, Dental School, Tehran University of Medical Sciences, Tehran, Iran

${ }^{4}$ Department of Internal Medicine and Endocrinology, Medical Faculty, Aja University of Medical Sciences, Tehran, Iran

${ }^{5}$ Department of Epidemiology and Biostatistics, Faculty of Public Health, Dental School, Tehran University of Medical Sciences, Tehran, Iran

Eur J Dent 2020;14:85-91
Address for correspondence Mehrzad Gholampour Dehaki, MD, MS, Department of Internal Medicine and Endocrinology, Medical Faculty, Aja University of Medical Sciences, Kargar St., Tehran, Iran (e-mail: mehr_ghol@yahoo.com).

\begin{abstract}
Keywords

- dental bleaching

- dental materials

- glass ionomer

- composite resins

- toothpastes

- blue covarine

Objectives This study aimed to assess the effect of an optical whitening toothpaste on color stability of microhybrid, nanofilled, and microfilled composite resins and resin-modified glass ionomer (RMGI) cement in comparison of two other toothpastes.

Materials and Methods In this experimental study, disc-shaped composite samples were fabricated. The samples were then polished using silicon carbide papers. Twenty-seven samples of each material were fabricated and subjected to colorimetry using a spectrophotometer. Each group of material was then divided into three subgroups for the application of conventional whitening and whitening containing blue covarine toothpastes. One operator brushed the samples with an electric soft toothbrush with circular motion twice a day, each time for 30 seconds. Colorimetry was performed at $0,1,7,30$, and 90 days.

Statistical Analysis Two-way analysis of variance (ANOVA), one-way ANOVA, and Tukey's honestly significant difference (HSD) test were used for statistical analysis.

Results The interaction effect of type of restorative material and time on $\Delta E$ was not significant at baseline or 1 day $(p>0.05)$. The effect of type of toothpaste on $\triangle \mathrm{E}$ was not significant at baseline or 1 day $(p=0.78)$ but the effect of type of material was significant $(p<0.05)$. The toothpastes had significantly different effects on $\Delta \mathrm{E}$ of $Z 250$ at all time points $(p<0.05)$ except for $\Delta E 0-30(p=0.106)$. The toothpastes had significantly different effects on $\triangle E$ of $Z 350$ and Gradia at all time points $(p<0.05)$. The same was true for RMGI except for $\Delta \mathrm{E} 0-7(p=0.43)$ and $\Delta \mathrm{E} 0-90(p=0.52)$. The majority of color changes caused by toothpastes were not clinically perceivable $(\Delta E$ $<3.3$ ), except for $\Delta E 0-90$ by the whitening toothpaste $(\Delta E=9), \Delta E 0-90$ by the conventional toothpaste for $Z 350(\Delta E=3.9)$, and $\Delta E 0-1$ by the whitening toothpaste for $\operatorname{RMGl}(\triangle \mathrm{E}=3.7)$.

Conclusion The color change of all composite samples was not clinically perceivable $(<3.3)$ at all time points, which shows that the tested toothpastes do not cause a significant change in color of composite materials.
\end{abstract}

License terms

()(1) $\Theta \circledast$ 


\section{Introduction}

Tooth color is an important parameter that plays a role in facial beauty. Some recent studies have shown that $17 \%$ to $53 \%$ of people from different populations are not satisfied with their tooth color. ${ }^{1-3}$

The available techniques to improve the appearance of discolored teeth include tooth bleaching, placement of crowns and veneers, professional cleaning by scaling and polishing to remove stains and tartar, and use of whitening toothpastes. The aforementioned techniques improve tooth color and dental esthetics via different mechanisms. ${ }^{4-7}$ The tooth bleaching techniques include in-office bleaching and at-home bleaching with the use of over-the-counter products that possess oxidizing properties. In the process of tooth bleaching, oxidizing agents penetrate into the enamel and dentin structure and become involved in chemical reactions. The goal of all bleaching agents, irrespective of their specific mechanism of action, is to deliver active components into the discolored parts of the tooth structure to eliminate the stains or bleach them. ${ }^{8}$

Whitening toothpastes have been designed for daily use to physically and chemically clean the tooth structure by removing stains or preventing their deposition. ${ }^{9,10}$ Toothpastes have several components to remove the stains or prevent their accumulation including abrasives, ${ }^{11}$ surfactants, calcium chelators, enzymes, and polymers. Recent studies have shown that abrasives are the primary cleaning agent in the composition of toothpastes. ${ }^{7,11}$

The literature is rich regarding the whitening toothpastes and evidence confirms their safety and different grades of efficacy. For instance, perlite was added to silica and calcium carbonate toothpastes as a cleanser and polisher and enhanced the stain removal efficacy of these toothpastes compared with nonwhitening toothpastes. Also, it did not cause unnecessary abrasion of enamel and dentin., ${ }^{9,12}$

Knowledge about the color science in dentistry and the relevant tools has led to advances in technology for dental bleaching and tooth whitening. ${ }^{7}$

The Commission Internationale de l'Eciairage (CIE) introduced the three-dimensional (3D) color space in 1975 to enhance color perception. This system uses the three axes of $L^{*}, a^{*}$, and $b^{*}$. The $L^{*}$ parameter indicates lightness while the $a^{*}$ and $b^{*}$ parameters indicate the redness-greenness and yellowness-blueness, respectively. ${ }^{13}$

Studies on tooth bleaching with peroxide products have demonstrated that changes in yellowness-blueness axis of tooth color are important and should be taken into account to assess the degree of tooth whitening. For instance, Gerlach et $\mathrm{al}^{14}$ evaluated the whitening response of two teeth to bleaching with products containing hydrogen peroxide after 2 weeks. They measured the tooth color before and after the treatment and filled out a questionnaire after the intervention. Data were compared with a model and they concluded that individual whitening responses to bleaching and patient satisfaction were significantly correlated with the changes in $\mathrm{b}^{*}$ value and not the $\mathrm{L}^{*}$ value or $\mathrm{a}^{*}$ value. Thus, changes in yellowness-blueness axis are important to assess the efficacy of vital tooth whitening products. ${ }^{15}$ Moreover, Kleber et $\mathrm{al}^{16}$ in an in vitro study used $1 \%$ hydrogen peroxide and showed that reduction in $b^{*}$ value was greater and occurred faster than the changes in $\mathrm{L}^{*}$ value. Evidence shows that the $b^{*}$ value is a more important parameter in tooth whitening. Goodson et al, in their clinical study on tooth whitening, stated that the bleaching agents significantly decreased the $b^{*}$ value (yellowness) while they caused an increase in $\mathrm{L}^{*}$ value.,17

Researchers believe that application of blue-colored substances on the tooth surface causes the desired changes in terms of optical properties of the teeth and particularly causes a color shift from yellow to blue. Thus, a spectrum of blue colors and pigments are commonly tested in laboratories for use in oral hygiene products to assess their effect on the $\mathrm{b}^{*}$ value and its alterations.

Blue covarine is the most effective substance used for significant reduction of $b^{*}$ value. Chemically-analyzed samples have shown that blue covarine deposits on the enamel surface. Further in vitro studies on extracted teeth have shown that treatment with blue covarine causes a significant reduction in $b^{*}$ value compared with the control group.

Changes in CIE Laboratory color parameters can be used to assess the efficacy of tooth whitening. A previous study showed that blue covarine significantly enhanced tooth whitening compared with the control group. Optical measurements after treatment with blue covarine demonstrated that teeth treated with blue covarine were whiter compared with their baseline state. Thus, blue covarine causes optical changes in color parameters, conferring a whiter appearance to the teeth.

Tooth whitening agents are available in different forms in the market. Blue covarine has been added to silica-based toothpastes in different concentrations in a laboratory. ${ }^{1}$ A previous study used extracted human teeth and brushed them with blue covarine dissolved in water and measured the color parameters. They indicated that high concentrations of blue covarine significantly decreased the yellowness and increased the whiteness of teeth. ${ }^{1,7}$

In 2008, Joiner et al evaluated the cleaning efficacy of a silica-based whitening toothpaste containing blue covarine and the associated abrasion of enamel and dentin. They concluded that the toothpaste was effective for stain removal and did not cause unnecessary abrasion of enamel and dentin compared with similar products. ${ }^{18}$

Covarine is a pigment used in hygienic and cosmetic products. Blue covarine (CI 74160; pigment blue 15, phthalocyanine blue) is incorporated in the composition of optical whitening toothpastes such as Signal, Colgate and Close Up.

On the other hand, to the best of authors' knowledge, there is a gap of information regarding the effect of long-term use of these toothpastes on color of teeth and restorative materials. Considering the high demand for tooth bleaching, high cost of this treatment and the need for retreatment after 1 to 3 years, it seems imperative to assess the efficacy of alternative treatments such as the use of whitening toothpastes. These toothpastes are low cost and easy to use, and preserve the tooth color for a longer period of time after the bleaching treatment. Thus, this study aimed to assess the effect of a toothpaste containing blue covarine on color stability of 
microfilled, nanofilled, and microhybrid composite resins and resin-modified glass ionomer (RMGI) cement at $0,1,7$, 30 , and 90 days after use. The null hypotheses were (1) type of toothpaste would have no significant effect on color of restorative materials at $0,1,7,30$, and 90 days after use and (2) type of restorative material would have no significant effect on color change at $0,1,7,30$, and 90 days after use.

\section{Materials and Methods}

Microhybrid, microfilled, and nanofilled composite resins and RMGI cement were used in this in vitro, experimental study ( - Table $\mathbf{1}$ ).

A2 shade disc-shaped composite samples with $2 \mathrm{~mm}$ thickness and $10 \mathrm{~mm}$ diameter were fabricated using a plexiglass mold. The mold was placed on a glass slab and a Mylar strip and filled with composite. Another glass slab was placed over it and compressed to eliminate voids. The samples were light-cured using a light curing unit (Valo; Ultradent, United States) with a light intensity of 1100 $\mathrm{mW} / \mathrm{cm}^{2}$ for 20 seconds from each side of the mold.

A total of 108 samples were fabricated as such (27 samples from each material). After removal of the Mylar strip, one operator polished the samples using 1,000, 2,000, 3,000 , and 5,000-grit silicon carbide papers. For completion of polymerization, the samples were immersed in distilled water for 24 hours. Samples made of each composite were randomly divided into three subgroups for toothbrushing with conventional whitening and whitening containing blue covarine toothpastes $(n=9)$ (-Table 1$)$. The amount of toothpaste used was $0.25 \mathrm{~g}$, which was diluted with water in 1:3 ratio. One operator brushed the samples twice a day, each time for 30 seconds. An electric toothbrush with circular motion was used for this purpose. The samples were then rinsed under running water. After the two tooth-brushing procedures, the artificial saliva was refreshed. The samples were stored in artificial saliva in a dark glass vial at room temperature during the experiment. Baseline colorimetry was performed by measuring the baseline $L^{*}, a^{*}$, and $b^{*}$ parameters using a spectrophotometer (X-Rite; Grandville, Michigan, United States). The color of samples was measured at $0,1,7,30$, and 90 days after toothbrushing with the respective toothpastes.

\section{Calculation of Change in Color Parameters}

The color of samples was measured according to the CIE L*a*b* color parameters using a spectrophotometer at the abovementioned time points. The $\mathrm{L}^{*}$ parameter indicates lightness, the $\mathrm{a}^{*}$ parameter indicates redness-greenness, and the $b^{*}$ parameter indicates yellowness-blueness. The overall color change $(\Delta \mathrm{E})$ of the samples was calculated using the formula below:

$$
\Delta E=\left(\Delta l^{2}+\Delta a^{2}+\Delta b^{2}\right)^{1 / 2}
$$

Table 1 Characteristics of the materials used in this study

\begin{tabular}{|c|c|c|c|}
\hline Material & Type & Content & Manufacturer \\
\hline Filtek Z250 & $\begin{array}{l}\text { Microhybride } \\
\text { metacrylate-based } \\
\text { composite }\end{array}$ & $\begin{array}{l}\text { BisGMA (bisphenol A diglycidyl ether dimethacrylate) and } \\
\text { a low-viscosity resin called TEGDMA, UDMA (urethane di- } \\
\text { methacrylate), and bis-EMA (bisphenol A polyethylene glycol } \\
\text { diether dimethacrylate) }\end{array}$ & $\begin{array}{l}\text { 3M ESPE, St. Paulm, MN, } \\
\text { United States }\end{array}$ \\
\hline Filtek Z350 XT Enamel & $\begin{array}{l}\text { Nanofilled } \\
\text { metacrylate-based } \\
\text { composite }\end{array}$ & $\begin{array}{l}\text { Bis-GMA, UDMA, } \\
\text { TEGDMA, and bis-EMA(6) } \\
\text { The fillers are a combination of nonagglomerated/nonag- } \\
\text { gregated } 20 \mathrm{~nm} \text { silica filler, } \\
\text { nonagglomerated/nonaggregated } 4-11 \mathrm{~nm} \text { zirconia filler, } \\
\text { and aggregated zirconia/silica } \\
\text { cluster filler (comprised of } 20 \mathrm{~nm} \text { silica and } 4-11 \mathrm{~nm} \text { zirconia } \\
\text { particles). }\end{array}$ & $\begin{array}{l}\text { 3M ESPE, St. Paulm, MN, } \\
\text { United States }\end{array}$ \\
\hline Anterior Gradia & $\begin{array}{l}\text { Microfilled Hybrid } \\
\text { Composite Resin }\end{array}$ & $\begin{array}{l}\text { 7,7,9 (or 7,9,9)-trimethyl-4,13-dioxo-3,14-dioxa-5,12-diaza- } \\
\text { hexadecane-1,16-diyl bismethacrylate }\end{array}$ & $\begin{array}{l}\text { GC Fuji II LC, } \\
\text { Corporation, Japan }\end{array}$ \\
\hline $\begin{array}{l}\text { Resin-modified Glass } \\
\text { ionomer }\end{array}$ & Resin-modified & $\begin{array}{l}\text { 2-hydroxyethyl methacrylate } \\
\text { tartaric acid } \\
\text { 7,7,9 (or 7,9,9)-trimethyl-4,13-dioxo-3,14-dioxa-5,12-diaza- } \\
\text { hexadecane-1,16-diyl bismethacrylate }\end{array}$ & $\begin{array}{l}\text { GC Fuji II LC, } \\
\text { Corporation, Japan }\end{array}$ \\
\hline $\begin{array}{l}\text { Colgate fluoride } \\
\text { toothpaste }\end{array}$ & $\begin{array}{l}\text { Maximum cavity } \\
\text { protection }\end{array}$ & $\begin{array}{l}\text { Calcium carbonate, aqua, sorbitol, sodium lauryl sulfate, so- } \\
\text { dium monofluorophosphate, aroma, cellulose gum, sodium } \\
\text { bicarbonate, tetrasodiumpyrophosphate, benzyl alcohol, } \\
\text { sodium saccharin, sodium hydroxide, limonene }\end{array}$ & $\begin{array}{l}\text { Colgate- Palmolive } \\
\text { (Thailand) Limited }\end{array}$ \\
\hline $\begin{array}{l}\text { Colgate antibacterial } \\
\text { and fluoride tooth- } \\
\text { paste (Colgate Total) }\end{array}$ & Whitening & $\begin{array}{l}\text { Aqua, glycerin, hydrated silica, pvm/ma copolymer, sodium } \\
\text { lauryl sulfate, aroma, cellulose gum, microcrystalline } \\
\text { cellulose, sodium hydroxide, carrageenan, sodium fluoride, } \\
\text { triclosan, sodium saccharin, mica, limonene, Cl 77891, Cl } \\
42090\end{array}$ & $\begin{array}{l}\text { Colgate- Palmolive } \\
\text { (Poland) }\end{array}$ \\
\hline Colgate & Optic White & $\begin{array}{l}\text { Aqua, hydrated silica, glycerin, sorbitol, PEG-12, pentasodi- } \\
\text { um triphosphate, tetrapotassium pyrophosphate, sodium } \\
\text { lauryl sulfate, aroma, cellulose gum, cocamidopropyl } \\
\text { betaine, sodium flouride, sodium saccharin, xanthan gum, } \\
\text { sodium hydroxide, limonene, CI74160 }\end{array}$ & $\begin{array}{l}\text { Colgate- Palmolive } \\
\text { (Poland) }\end{array}$ \\
\hline
\end{tabular}




\section{Statistical Analysis}

Data were analyzed using SPSS version 18 (IBM cooperation, New York, United States). The measures of central dispersion including the mean, standard deviation, minimum, and maximum values of color parameters of different restorative materials at different time points were reported and the relevant tables and graphs were drawn. Two-way ANOVA was applied to assess the effect of type of restorative material, time, and the interaction of the two on different color parameters as well as $\Delta \mathrm{E}$. In case of presence of a significant difference, pairwise comparisons were performed using Tukey's HSD test. Level of significance was set at 0.05 .

\section{Results}

Assessment of $\Delta \mathrm{E}$ at baseline (time 0 ) and 1 day revealed no significant difference $(p>0.05)$. In other words, type of toothpaste had no significant effect on $\Delta \mathrm{E} 1-0(p=0.78)$. However, the effect of type of restorative material on $\Delta \mathrm{E}$ was significant $(p<0.05)$.

The three toothpastes were significantly different in terms of their effect on $\triangle \mathrm{E}$ of $\mathrm{Z} 250(p<0.05)$ except for $\Delta \mathrm{E} 30-0(p=0.106)$. Comparison of the effects of toothpastes on $\Delta \mathrm{E}$ of $\mathrm{Z} 250$ revealed that the difference between the whitening toothpaste and whitening toothpaste containing blue covarine on $\Delta \mathrm{E} 7-0$ was not significant $(p=0.197)$. Comparison of toothpastes revealed no significant difference in their effect on $\triangle \mathrm{E} 30-0(\mathrm{P}>0.05)$. Comparison of the conventional toothpaste and the whitening toothpaste containing blue covarine revealed no significant difference in their effect on $\Delta \mathrm{E} 90-0(p=0.126)$. However, the difference in this respect between the conventional toothpaste and the whitening toothpaste containing blue covarine was significant. For Z250 samples, the whitening toothpaste was able to cause clinically perceivable change in color at 90 days $(\Delta \mathrm{E} 90-0)$.
The three toothpastes were significantly different regarding their effect on $\Delta \mathrm{E}$ of $\mathrm{Z350}(p<0.05)$. Comparison of toothpastes revealed a significant difference with regard to $\Delta \mathrm{E} 7-0$ $(p<0.05)$ but no significant difference was noted for $\Delta \mathrm{E} 30-7$. The difference between the whitening toothpaste and the one containing blue covarine was not significant with regard to $\Delta \mathrm{E} 30-0(p=0.448)$. The difference between the whitening toothpaste and the blue covarine toothpaste was not significant for $\Delta \mathrm{E} 90-0$ ( $p=0.188$ ). For Z350 samples, only the conventional toothpaste caused clinically perceivable color change $(\Delta \mathrm{E}=3.9)$ at 90 days $(\Delta \mathrm{E} 90-0)$.

The three toothpastes were significantly different in terms of their effect on $\Delta \mathrm{E}$ of Gradia at all time points $(p<0.05)$. The three toothpastes were significantly different with regard to their effect on $\Delta \mathrm{E} 7-0(p<0.05)$ and $\Delta \mathrm{E} 30-0(p<0.05)$ for Gradia. However, the difference between the whitening and the conventional toothpastes was not significant for $\Delta \mathrm{E} 90-0$ $(p=0.317)$. None of the $\Delta \mathrm{E}$ values for Gradia were within the acceptability threshold range $(\Delta \mathrm{E}<3.3)$.

For RMGI samples, the toothpastes were not significantly different regarding their effect on $\Delta \mathrm{E} 7-0(p=0.43)$ and $\Delta$ E90-0 $(p=0.52)$. The whitening toothpaste caused color change out of acceptability threshold $(\Delta \mathrm{E}=3.7)$ in RMGI samples on day $1(\Delta \mathrm{E} 1-0)$ (-Figs. 1-4).

\section{Discussion}

This study aimed to assess the effect of three types of toothpastes, namely, a conventional toothpaste, a whitening toothpaste, and another whitening toothpaste containing blue covarine on color stability of four types of restorative materials, namely, a nanofilled (Z350 XT), a microhybrid (Z250), a microfilled (Gradia) composite, and an RMGI cement (Fuji II LC).

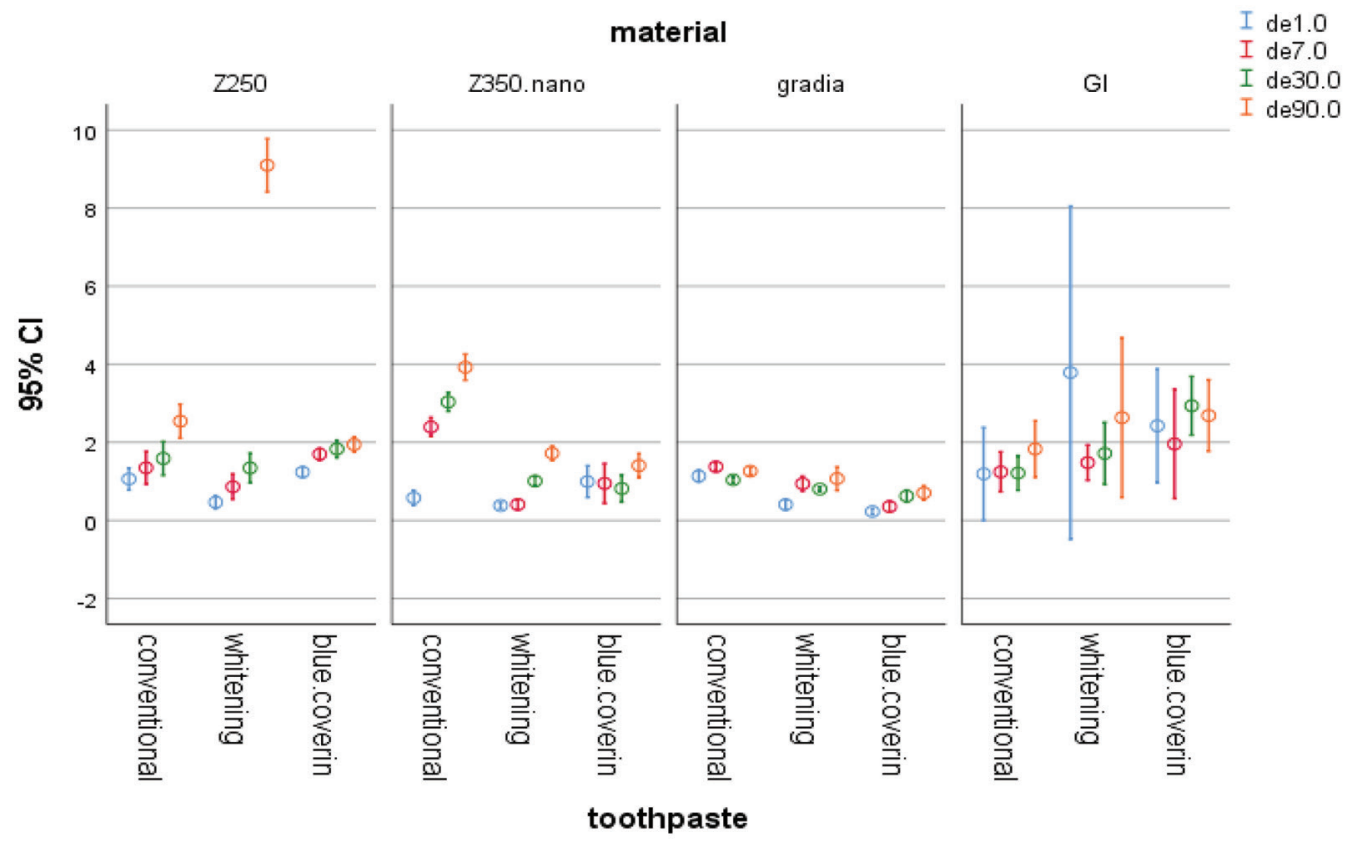

Fig. 1 The $95 \% \mathrm{Cl}$ of color change $(\Delta \mathrm{E})$ of materials at different time points. $\mathrm{Cl}$, confidence interval. 


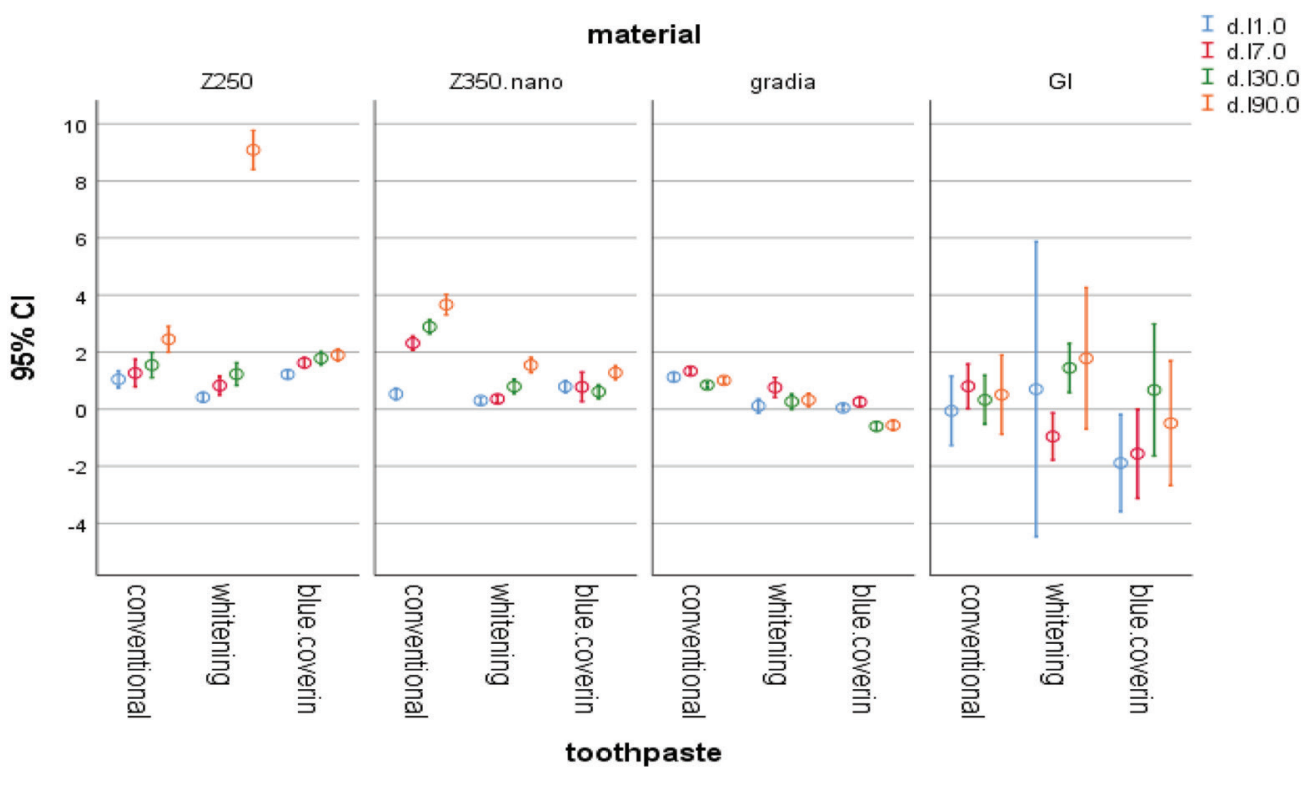

Fig. 2 The $95 \% \mathrm{Cl}$ of change in $\mathrm{L}^{*}$ parameter of materials at different time points. Cl, confidence interval.

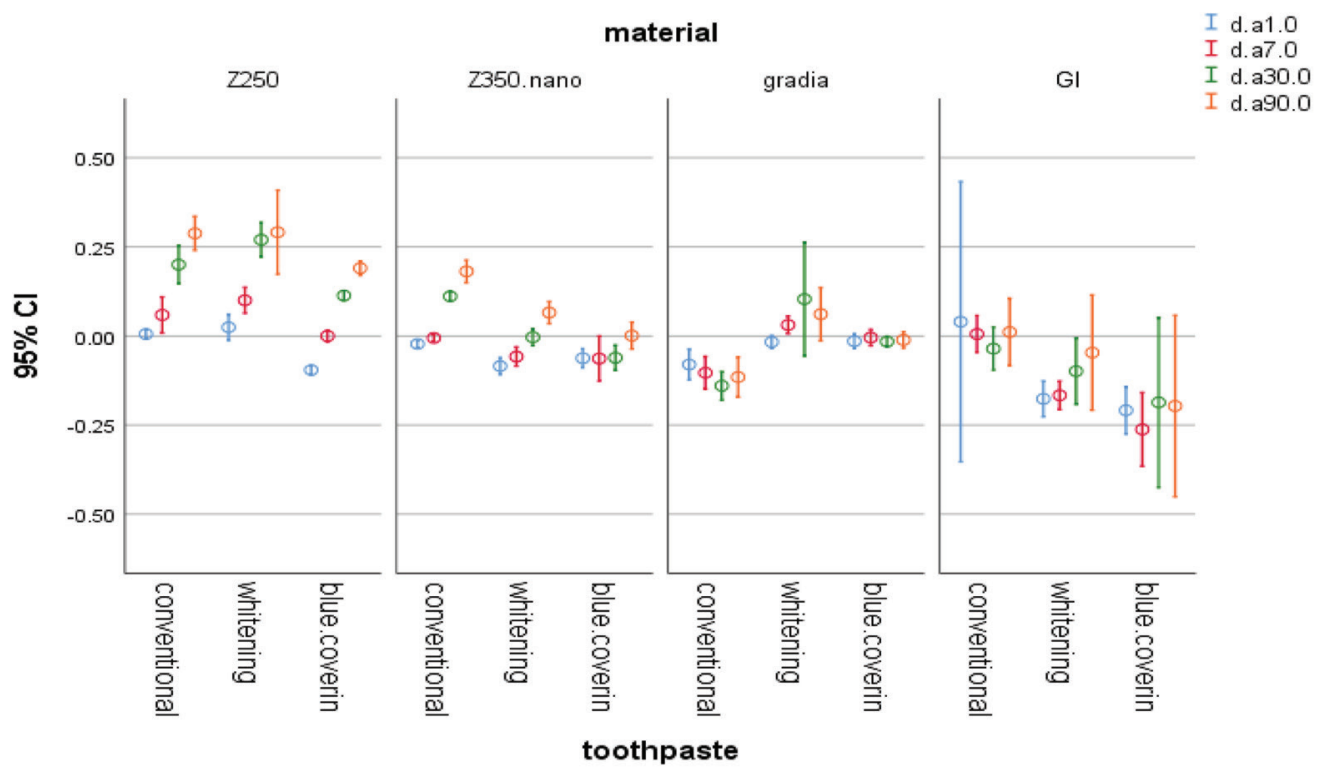

Fig. 3 The $95 \% \mathrm{Cl}$ of change in a* parameter of materials at different time points. $\mathrm{Cl}$, confidence interval.

The color of samples was measured at $0,1,7,30$, and 90 days after toothbrushing with the abovementioned toothpastes. As shown in - Fig. 1 , the $\Delta \mathrm{E}$ of all composite samples was within acceptability threshold range at all time points $(\Delta \mathrm{E}<3.3)$. This finding shows that these toothpastes do not cause a significant change in color of composite resins. However, they caused a significant change in color of RMGI samples at 1 and 7 days.

In this study, baseline colorimetry of samples revealed a significant difference among them, which may be due to their different composition. A previous study that individual whitening responses to bleaching and satisfaction of patients were significantly associated with changes in $b^{*}$ value but not $\mathrm{L}^{*}$ value or $\mathrm{a}^{*}$ value. In the present study, use of whitening toothpastes did not cause a significant color change in composite samples; however, the whitening toothpaste and the toothpaste containing blue covarine both caused a reduction in $\mathrm{b}^{*}$ value in almost all composite and RMGI samples. This indicates the optimal efficacy of these toothpastes in decreasing the yellowness of composite resins used in this study. However, this was not the case for the effect of conventional toothpaste on Gradia composite and RMGI since the whitening toothpastes increased the yellowness of these samples. This finding can be due to the aging of these composites over time and the consequent changes in their color parameters including the $b^{*}$ value. 


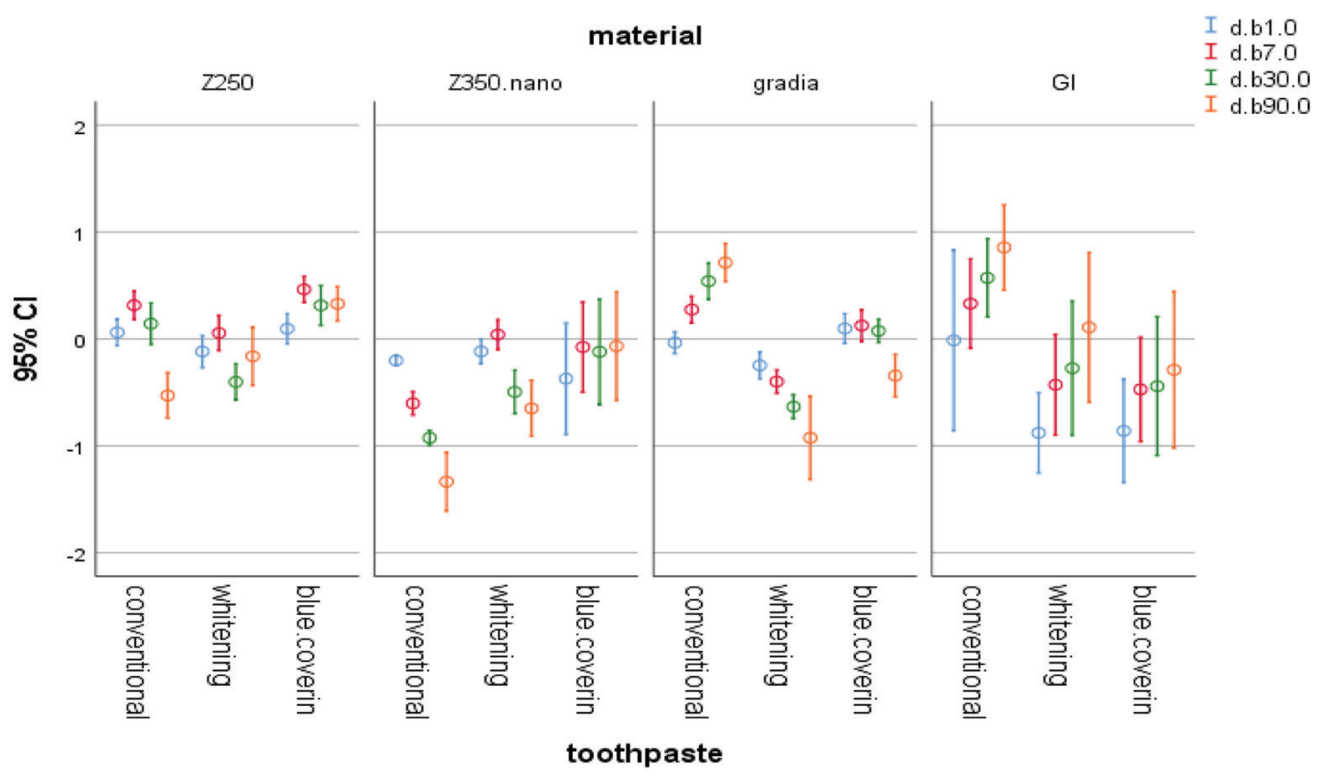

Fig. 4 The $95 \% \mathrm{Cl}$ of change in b* parameter of materials at different time points. $\mathrm{Cl}$, confidence interval.

Application of whitening toothpastes on RMGI samples did not decrease the $b^{*}$ value; instead, it increased the yellowness of samples. This finding was probably attributed to the structural differences of RMGI and composite resins. Composite resins are composed of organic polymer matrix and inorganic filler particles, which are attached to each other via the coupling agents and form a polymer network after polymerization. However, glass ionomers have an aqueous base and fluoroaluminosilicate glass fillers. They have a polymer or copolymer matrix of carboxylic acids and have acidbase setting reaction. A methacrylate component has been added to this composition in RMGI cement. In general, the physical and mechanical properties of glass ionomers such as their wear resistance and dimensional stability are inferior to those of composite resins. ${ }^{19}$ It seems that water sorption and aging due to passage of time also had an effect on the results obtained for RMGI samples in the present study.

Al-Shalan showed that application of Colgate, Aqua Fresh Ultimate White, and Crest 3D white toothpastes twice a day for 2 minutes for a total of 15 days caused a significant color change in Z250XT, GC Fuji II LC, and Ketac Molar Quick Aplicap. ${ }^{20}$ In our study, color change occurred at a longer time (90 days) in Z250 and Z350XT.

Teixeira et al (2005) ${ }^{21}$ applied restorative materials in standard molds to standardize the size and shape of samples and placed the molds between two Mylar strips and glass slabs. The same methodology was adopted in our study. Also, we stored the samples in artificial saliva, similar to the study by Joiner et al. ${ }^{18}$

For assessment of color stability, colorimetry was performed using a spectrophotometer, which displayed $\Delta \mathrm{E}$ of each sample on a display monitor. Use of spectrophotometer for this purpose in our study was similar to previous studies. $^{22,23}$ However, some other studies measured the change in color by analyzing digital images or use of a colorimeter. ${ }^{1,18,24,25}$ In the present study, different toothpastes caused color change in acceptability threshold or out of acceptability threshold after 90 days (Z350 showed perceivable color change after brushing with the conventional toothpaste for 90 days and Z250 showed perceivable color change after brushing with the whitening toothpaste for 90 days). It appears that this finding is more related to aging due to longterm immersion rather than the composition of toothpastes.

In vitro design was a limitation of this study, which has differences with the intraoral environment. ${ }^{26}$ However, we tried our best to standardize the study settings and simulated long-term use of toothpastes and their effect on color of restorations.

Danying Tao et al, in 2017, concluded that toothpastes containing blue covarine or a combination of blue covarine and FD\&C blue No.1 significantly increase the whiteness of teeth immediately after tooth brushing both in vitro and in the clinical setting. ${ }^{27}$ Our study revealed clinically perceivable color change after 90 days, but no changes were noticed at 1,7 , or 30 days.

\section{Conclusion}

The color change of composite samples at all time points evaluated in this study was within the acceptable threshold range $(<3.3)$. This finding indicates that these toothpastes do not cause a significant color change in composite restorations. However, a significant color change occurred in RMGI samples at 1 and 7 days after using the whitening toothpastes.

\section{Conflict of Interest}

None declared. 


\section{References}

1 Joiner A, Philpotts CJ, Alonso C, Ashcroft AT, Sygrove NJ. A novel optical approach to achieving tooth whitening. J Dent 2008;36(Suppl 1):S8-S14

2 Alkhatib MN, Holt R, Bedi R. Age and perception of dental appearance and tooth colour. Gerodontology 2005;22(1):32-36

3 Xiao J, Zhou XD, Zhu WC, Zhang B, Li JY, Xu X. The prevalence of tooth discolouration and the self-satisfaction with tooth colour in a Chinese urban population. J Oral Rehabil 2007;34(5):351-360

4 Joiner A. The bleaching of teeth: a review of the literature. J Dent 2006;34(7):412-419

5 Sarrett DC. Tooth whitening today. J Am Dent Assoc 2002;133(11):1535-1538, quiz 1541

6 Berman LH. Intrinsic staining and hypoplastic enamel: etiology and treatment alternatives. Gen Dent 1982;30(6):484-488

7 Joiner A. A silica toothpaste containing blue covarine: a new technological breakthrough in whitening. Int Dent J 2009;59(5):284-288

8 Schwartz MS, Andrasik F. Biofeedback: A Practitioner's Guide. New York: NY: Guilford Publications; 2017

9 Joiner A. Review of the extrinsic stain removal and enamel/ dentine abrasion by a calcium carbonate and perlite containing whitening toothpaste. Int Dent J 2006;56(4):175-180

10 Wülknitz P. Cleaning power and abrasivity of European toothpastes. Adv Dent Res 1997;11(4):576-579

11 Joiner A. The cleaning of teeth. In: Handbook for Cleaning/ Decontamination of Surfaces. 2007;1:371-405

12 Joiner A, Pickles MJ, Matheson JR, Weader E, Noblet L, Huntington E. Whitening toothpastes: effects on tooth stain and enamel. Int Dent J 2002;52(S5):424-430

13 Joiner A. Whitening toothpastes: a review of the literature. J Dent 2010;38(Suppl 2):e17-e24

14 Gerlach RW, Barker ML, Sagel PA. Objective and subjective whitening response of two self-directed bleaching systems. Am J Dent 2002;15(Spec No):7A-12A

15 Gerlach RW, Gibb RD, Sagel PA. A randomized clinical trial comparing a novel $5.3 \%$ hydrogen peroxide whitening strip to $10 \%, 15 \%$, and $20 \%$ carbamide peroxide tray-based bleaching systems. Compend Contin Educ Dent Suppl 2000;(29):S22-S28, quiz S42-S43

16 Kleber CJ, Putt MS, Nelson BJ. In vitro tooth whitening by a sodium bicarbonate/peroxide dentifrice. J Clin Dent 1998;9(1):16-21

17 Goodson JM, Tavares M, Sweeney M, et al. Tooth whitening: tooth color changes following treatment by peroxide and light. J Clin Dent 2005;16(3):78-82

18 Joiner A, Philpotts CJ, Ashcroft AT, Laucello M, Salvaderi A. In vitro cleaning, abrasion and fluoride efficacy of a new silica based whitening toothpaste containing blue covarine. J Dent 2008;36(Suppl 1):S32-S37

19 Powers JM. Craig's restorative dental materials. In: Mechanical Properties. United States: Mosby; 2006:51-96

20 Al-Shalan T. Effect of whitening toothpastes on color stability of different restorative materials. Int J Medical Science Clinical Invention 2017;4(3).https://doi.org/10.18535/ijmsci/v4i3.13

21 Teixeira EC, Thompson JL, Piascik JR, Thompson JY. In vitro toothbrush-dentifrice abrasion of two restorative composites. J Esthet Restor Dent 2005;17(3):172-180, discussion 181-182

22 Torres CR, Perote LC, Gutierrez NC, Pucci CR, Borges AB. Efficacy of mouth rinses and toothpaste on tooth whitening. Oper Dent 2013;38(1):57-62

23 Dantas AA, Bortolatto JF, Roncolato Á, et al. Can a bleaching toothpaste containing Blue Covarine demonstrate the same bleaching as conventional techniques? An in vitro, randomized and blinded study. J Appl Oral Sci 2015;23(6):609-613

24 Ashcroft AT, Cox TF, Joiner A, et al. Evaluation of a new silica whitening toothpaste containing blue covarine on the colour of anterior restoration materials in vitro. J Dent 2008;36(Suppl 1):S26-S31

25 Collins LZ, Naeeni M, Platten SM. Instant tooth whitening from a silica toothpaste containing blue covarine. J Dent 2008;36(Suppl 1):S21-S25

26 Eliades T, Eliades G, Silikas N, Watts DC. In vitro degradation of polyurethane orthodontic elastomeric modules. J Oral Rehabil 2005;32(1):72-77

27 Tao D, Sun JN, Wang X, et al. In vitro and clinical evaluation of optical tooth whitening toothpastes. J Dent 2017;67S:S25-S28 